\title{
EVALUATION OF STAINLESS STEEL 316L JOINTS WELDED BY LASER
}

\author{
A. M. Hussien ${ }^{1}$, Adel. B. El-Shabasy ${ }^{1}$ and Khalid M. Abd El-Ghany ${ }^{2}$ \\ ${ }^{1}$ Design and Production Department, Ainshams University, Cairo, Egypt \\ ${ }^{2}$ Department, Centeral Metallurgical Center and Research Institute, Helwan
}

\begin{abstract}
Continuous wave diode pumped Nd:YAG laser was applied to weld AISI 316L Stainless steel. Butt joint sheets of $1.5 \mathrm{~mm}$ thickness and $30 \mathrm{~mm}$ width were joined together in a single pass without using filler material. Design of experiment is applied to investigate the effects of laser power and welding speed on penetration depth and mechanical properties (tensile strength and microhardness). The depth of penetration is directly proportional to the laser power and inversely proportional with the welding speed. Maximum penetration depth was $753 \mu \mathrm{m}$. The tensile strength is directly proportional with the laser power. Maximum tensile strength is $632 \mathrm{MPa}$. Ductile fracture is revealed by SEM analysis. The average value of microhardness of the weld is $275 \mathrm{HV}$ while the average of the base metal reached $225 \mathrm{HV}$, this is because of the presence of different phases in weld metal from base metal.
\end{abstract}

\section{KEYWORDS : Laser welding, Stainless steel 316L, Microhardness, Tensile strength.}

\section{INTRODUCTION}

Austenitic stainless steels are one of the most commonly used materials in the industry, due to their service performance, high weldability, and economical nature. They mainly contain 16 to $26 \%$ chromium and up to $35 \%$ nickel, and this make them have a high corrosion resistance. One of the most common types is the $316 \mathrm{~L}$ grade that has high immunity from sensitization, and it is resistant to pitting and crevice corrosions in warm chloride environments and to stress corrosion cracking above $60{ }^{\circ} \mathrm{C}$. It has a good oxidation resistance up to about $900{ }^{\circ} \mathrm{C}$ in continuous work.

$\mathrm{Na}$ Zhang Liu and Walcott [1] made a series of experiments to investigate correlations between welding parameters and the weld pool geometry. Continuous Hammerstein identification methodology and error-based identification strategy were used to demonstrate significant nonlinearity in the diode laser welding process and it was found in both methods the model takes the reciprocal of the welding speed as the input and the top side surface width of the weld pool as the output.

Seang, David and Ragneau [2] studied the effect of Nd:YAG laser welding parameters on the hardness of lap joint. Interaction between various process parameters were observed and it was found that the laser parameters have strong influence on the hardness along the depth of the weld bead but they have no influence on the hardness inside the softening zone.

Wang et. al. [3] used the longitudinal three-point bending method to investigate the bending ductility of laser welded joint. It was clear from their experiments that as bending ductility increases the heat input by the laser beam welding decreases. The presence of fine and irregular grains leads to better crack propagation resistance and higher fracture strains. 
Sun et. al. [4] conducted laser beam welding of ferritic stainless steel 409L which showed various advantages such as HAZ was narrow and the grain growth degree was small. Moreover, it could well satisfy motor vehicle exhaust pipe production.

Khan et. al.[5] applied laser welding of 2 thin cylindrical shells of ferritic AISI430f and martensitic AISI440c. They stated that the weld penetration and width mainly increase at higher laser power values because this leads to higher energy deposition on the weld area, and the deposited energy will have longer time to diffuse in the material.

Xue et. al.[6] experimented pulsed Nd:YAG laser beam on CNC machined and sanded $1 \mathrm{~mm}$ thick DP1000 steel and reported that high penetration rate can be achieved when the range of laser power starts from $40 \%$ until it reaches $60 \%$, and penetration is most full at laser power greater than $60 \%$. However, microstructure observations contradicted the increase in welding penetration by decreasing welding speed. They explained that the temperature of the material increases with increasing welding speed while the cooling time decreases, hence the ability of the laser beam to penetrate the material is increased at higher welding speeds.

El-Batahgy et. al. [7] results showed that the fusion zone dimensions increase incredibly at lower welding speeds rather than higher speeds. El-Batahgy [8], Y.Feng et. al. [9] concluded from their experiments of laser welding on dissimilar stainless-steel joints that welding speed has an opposite effect on the laser beam penetration depth, and weld bead width.

Bolut Kong et. al. [10] reported after their trials to weld $6 \mathrm{~mm}$ thick duplex stainless steel of grade 2205 by $\mathrm{Yb}$-fibre continuous wave laser that full penetration is achieved below $4 \mathrm{~m} / \mathrm{min}$ when the laser power is $5 \mathrm{~kW}$, and 1 to $2 \mathrm{~m} / \mathrm{min}$ when the laser power is greater or equal to $4 \mathrm{~kW}$, and $0.5 \mathrm{~m} / \mathrm{min}$ at minimum power of $2.5 \mathrm{~kW}$.

\section{Experimental Procedure}

A rolled stainless steel $316 \mathrm{~L}$ sheet with $1.5 \mathrm{~mm}$ thickness is selected for the laser welding experiments. The dimensions of the workpiece are cut to $100 * 30 \mathrm{~mm}$ by wire EDM to obtain straight edges free of any burrs.

The materials are undergone spectroscopy chemical analysis test to obtain the chemical composition which is shown in Table 1.

Table 1 Chemical composition of 316L stainless steel

\begin{tabular}{ccccccccc}
\hline $\mathrm{C}$ & $\mathrm{Mn}$ & $\mathrm{P}$ & $\mathrm{S}$ & $\mathrm{Si}$ & $\mathrm{Cr}$ & $\mathrm{Ni}$ & $\mathrm{Mo}$ & $\mathrm{N}$ \\
\hline 0.03 & 0.97 & 0.072 & 0.006 & 0.49 & 16.86 & 9.73 & 2.05 & 0.12 \\
\hline
\end{tabular}

Rofin Sinar CW solid state Nd: YAG laser pump with maximum power of $2.2 \mathrm{~kW}$ and focal point $500 \mu \mathrm{m}$ is used for welding processes. The laser beam is delivered through a fiber optic cable which is connected to the focusing lens that is fixed in a robotic arm as shown in Figure 1 .

The specimens are prepared for butt joints to ensure that there is no air gap between the two pieces, then they are cleaned with ethyl alcohol to remove any impurities that may affect the

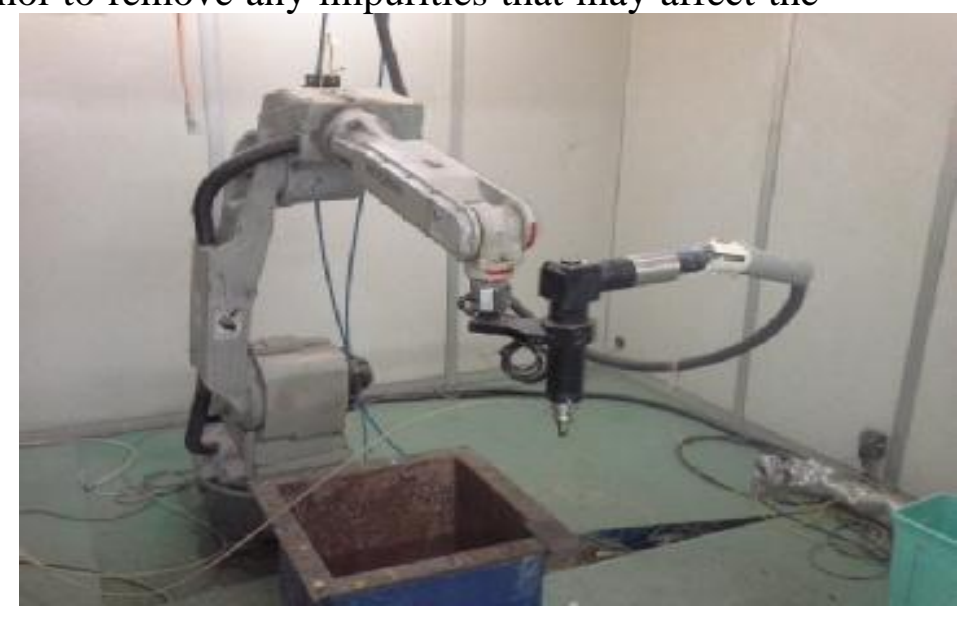

Figure 1 Laser welding robotic arm 
weld bead properties and are held in a custom fixture designed for the experiment and fixed by toggle clamps as shown in Figure 2 to prevent the distortion of welded samples by residual stresses. The gap between 2 parts are adjusted to be zero. Factorial experiment was designed between the values of the laser power and welding speed as shown in Table 2. Nitrogen is used as shield gas. The flow rate of the shield gas was kept constant at $301 / \mathrm{min}$ during the whole experiment.

Table 2 Experimental design of laser welding parameters

\begin{tabular}{cc|c}
\hline Laser Power $(\mathrm{W})$ & Head Speed $(\mathrm{m} / \mathrm{min})$ & \multirow{2}{*}{ Focal point position $(\mathrm{mm})$} \\
\hline \multirow{2}{*}{800} & 0.5 & \\
& 1 & \\
\multirow{2}{*}{1000} & 1.5 & \multirow{2}{*}{0} \\
& 0.5 & \\
\multirow{2}{*}{1200} & 1 & \\
& 1.5 & \\
\hline
\end{tabular}

The values of the laser power and speed are programmed in the machine. The track is positioned such that the weld line is straight. The height is adjusted to achieve zero focal point and in the middle weld line to equally distribute the power density and to prevent any probability of formation of a misaligned welded joint. To make sure that the power of the laser is stable, the process is started and ended 5 $\mathrm{mm}$ away from the samples. After the end of the welding process, the sample is kept for a short period to cool down and then the clamps are released to fix another

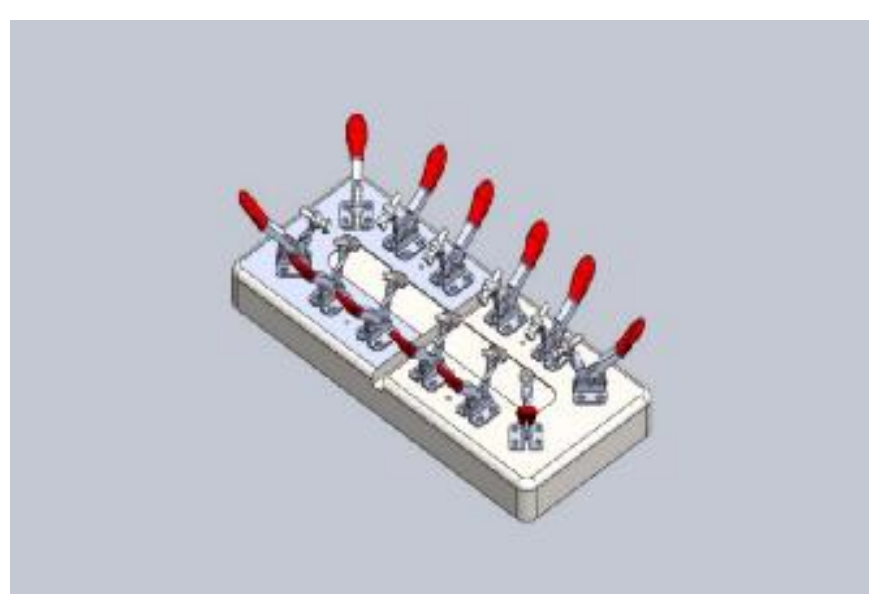

Figure 2 The designed model of the sample fixture sample.

Each sample is cut by wire EDM method to obtain straight and precise dimensions without the need of finishing. The tension samples were cut according to ASTM E8M-04 standard as shown in Figure 3 the strain rate of the test was adjusted at $4.5 \mathrm{~mm} / \mathrm{min}$.

Moreover, other samples were cut and prepared for macroscopic examination of the weld bead. The samples were electro etched by $10 \%$ oxalic acid to reveal the welded zone of the sample. Analysis has been performed using metallographic macroscope with image analysis

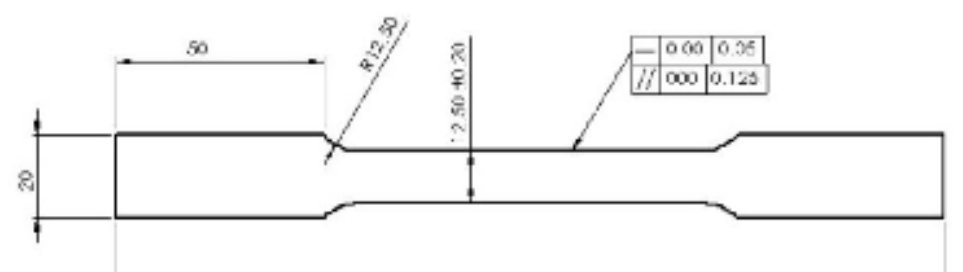

Figure 3 Standard tensile test specimen with the manufactured dimensions software.

Microhardness test is applied at 100 gram-force and dwell time 20 seconds and the distance between each indentation is adjusted to be $100 \mu \mathrm{m}$.

\section{Results and discussion}




\subsection{Effect of laser power}

The quality of the welded surface proved that there is no sign of any surface imperfection in the welded joints, and this is shown in Figure 4.
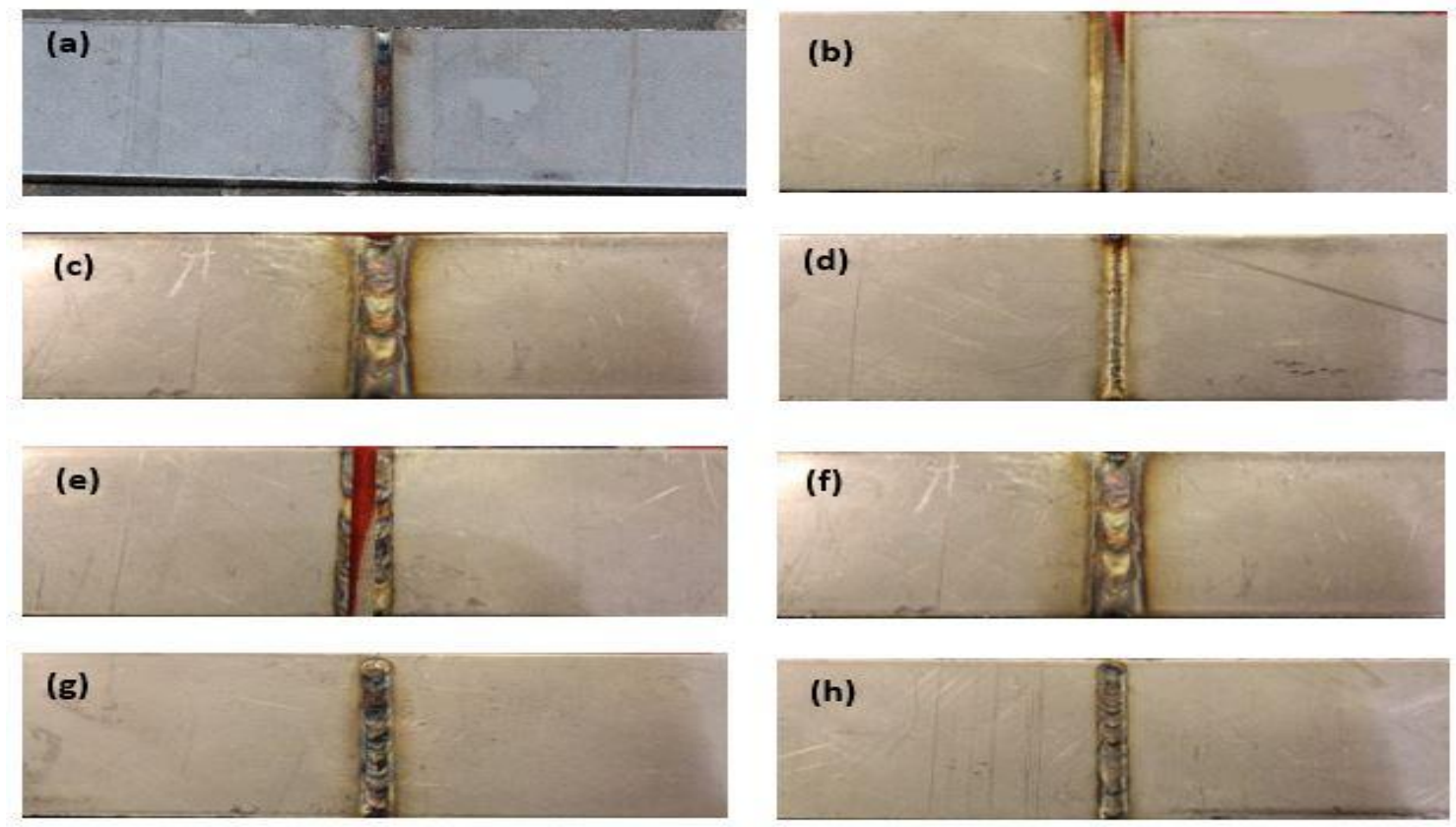

Figure 4 Welded joints at (a) $800 \mathrm{~W}, 0.5 \mathrm{~m} / \mathrm{min}$ (b) $800 \mathrm{~W}, 1 \mathrm{~m} / \mathrm{min}$ (c) $1000 \mathrm{~W}, 0.5 \mathrm{~m} / \mathrm{min}$ (d) $1000 \mathrm{~W}, 1$ $\mathrm{m} / \mathrm{min}$ (e) $1000 \mathrm{~W}, 1.5 \mathrm{~m} / \mathrm{min}$ (f) $1200 \mathrm{~W}, 0.5 \mathrm{~m} / \mathrm{min}$ (g) $1200 \mathrm{~W}, 1 \mathrm{~m} / \mathrm{min}$ (h) $1200 \mathrm{~W}, 1.5 \mathrm{~m} / \mathrm{min}$.

Figure 5 illustrates the effect of laser power on the penetration under two welding speeds. At zero focal point and $0.5 \mathrm{~m} / \mathrm{min}$, the penetration increases with increasing power from $800 \mathrm{~W}$ to $1000 \mathrm{~W}$, while increasing of power to $1200 \mathrm{~W}$ leads to decreasing the penetration depth to $687 \mu \mathrm{m}$. However, the width is wider and more constant along the depth of penetration as shown in Figure 6. This is because of convective heat transfer which leads to a

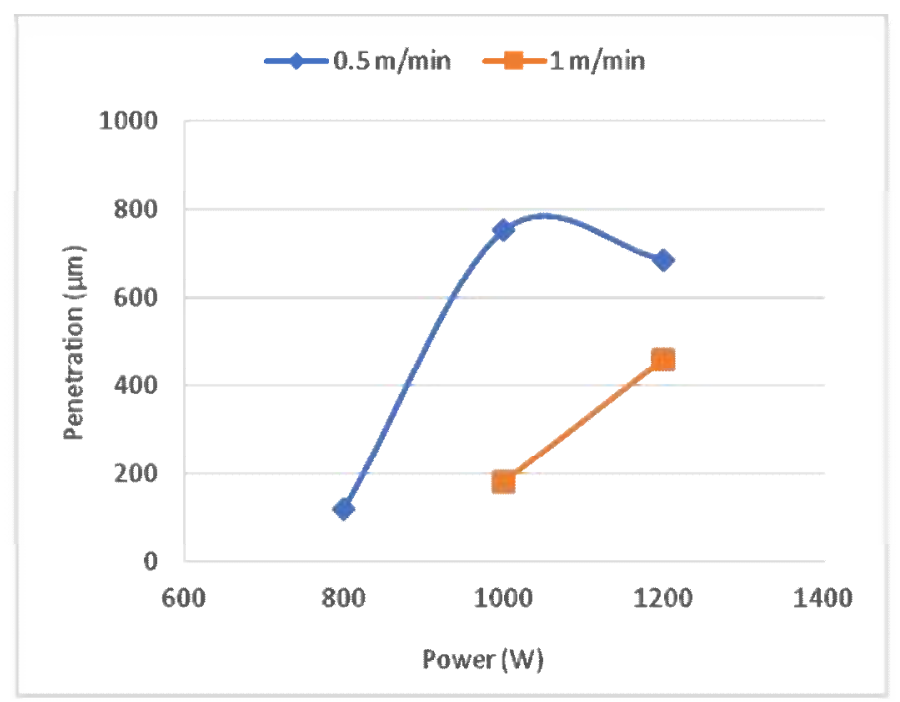

Figure 5 Effect of laser power on penetration 
decrease in penetration and increase in width. High heat input is transferred to the material which leads to melting of a greater area along the weld bead at the same depth. Khan et. al. [5] achieved at $1.47 \mathrm{~mm}$ at

$800 \mathrm{~W}$ and $2 \mathrm{~m} / \mathrm{min}$ and $1.6 \mathrm{~mm}$ at $1000 \mathrm{~W}$ and $2 \mathrm{~m} / \mathrm{min}$. While El Batahgy e. al. [7] achieved $3.5 \mathrm{~mm}$ at $4 \mathrm{~kW}$ and $3.7 \mathrm{~mm}$ at $5 \mathrm{KW}$.
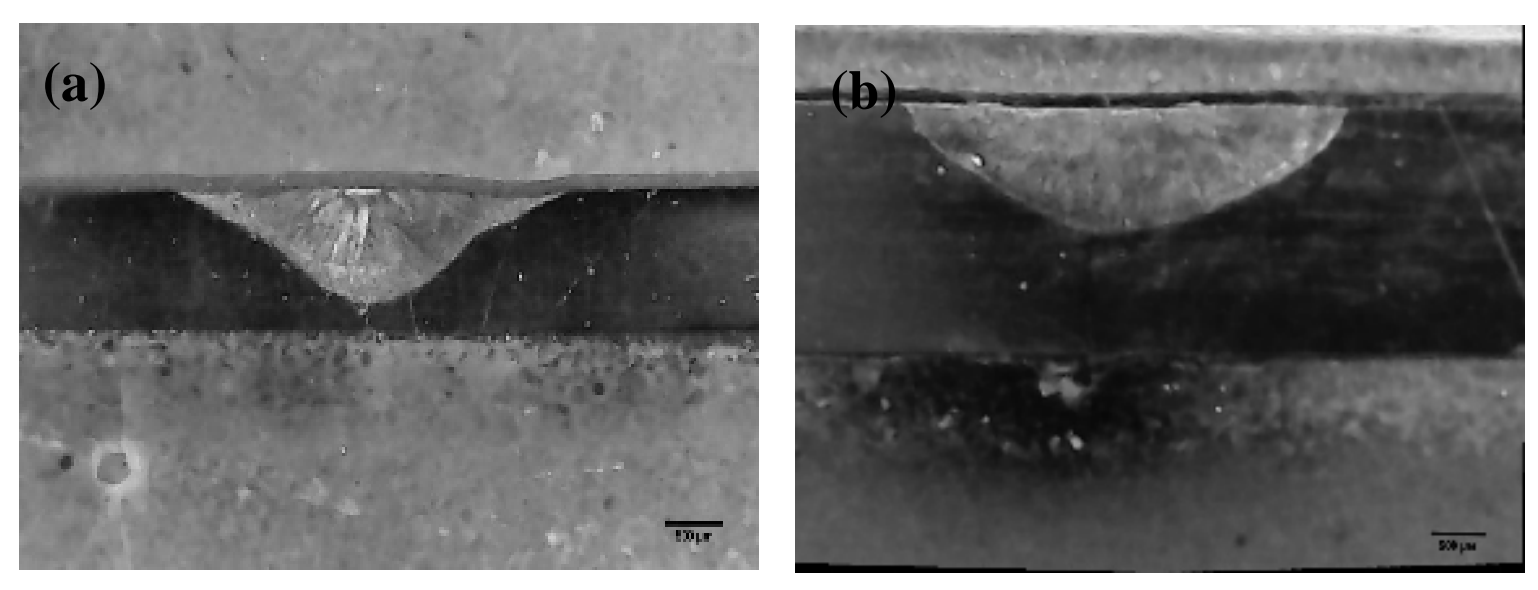

Figure 6 Macrograph of laser welded samples (a) at 1000W and (b) at 1200W

\subsection{Effect of welding speed}

Welding speed has a great influence on increasing or decreasing the interaction time between the beam and the material which results in controlling the heat input. At high speeds, less region of material will be subjected to heat, hence the depth of penetration will be shallow, and the opposite will occur at low speeds. Figure 7 explains the effect of welding speed on penetration at two laser powers 1000 $\mathrm{W}$ and $1200 \mathrm{~W}$. For $1000 \mathrm{~W}$ laser power, the penetration decreased from $753 \mu \mathrm{m}$ to $183 \mu \mathrm{m}$, and at $1200 \mathrm{~W}$ the penetration decreased from $686 \mu \mathrm{m}$ to $192 \mu \mathrm{m}$ and this is clear in Figure 8 . This may be as a result of the effect of welding speed on the fluid dynamics of the liquid metal [11]. At low speeds, more heat is generated inside the material (as a result of high heat

input) which causes the molten metal to transfer more heat from the center of the pool to the periphery of

the weld [12]. High heat input evaporates the metal, creating plasma shield that absorbs laser and decreases the delivered power to the metal, so the

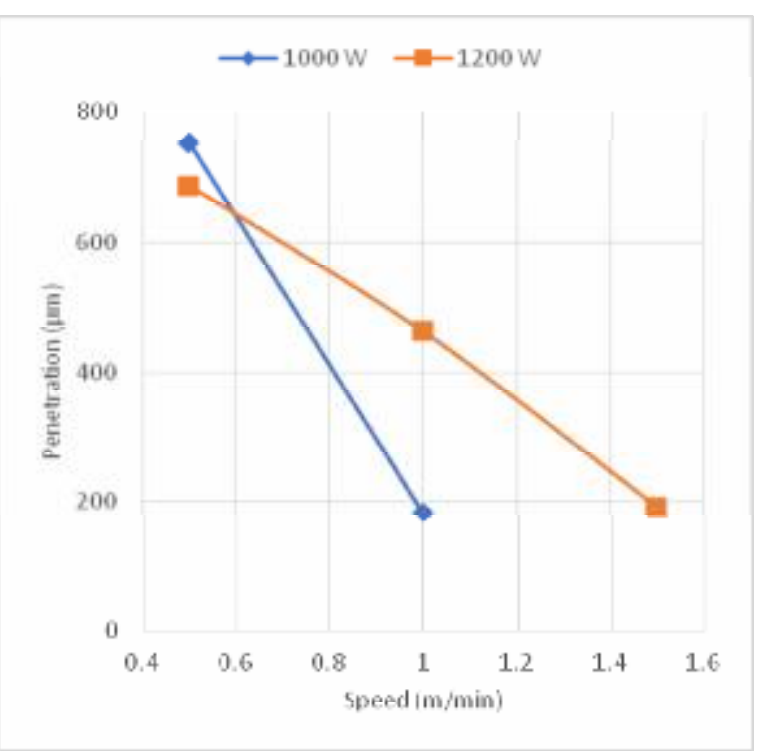

Figure 7 Effect of welding speed on penetration depth 

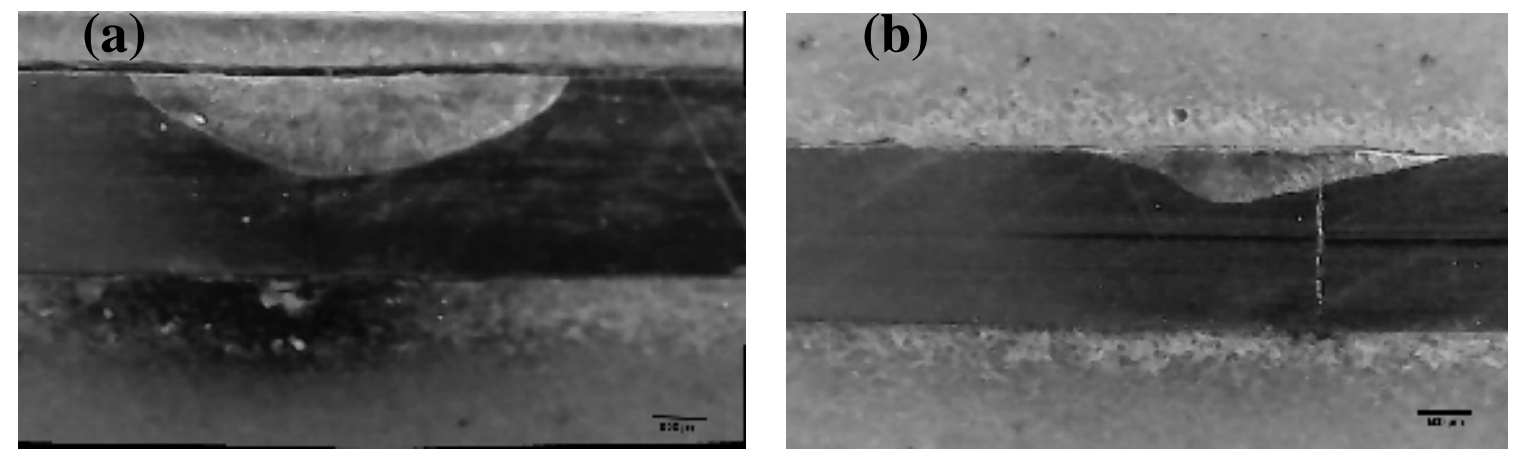

Figure 8 Macrograph of welded samples at (a) $0.5 \mathrm{~m} / \mathrm{min}$ and (b) $1 \mathrm{~m} / \mathrm{min}$.

penetration depth becomes less than expected. Khan et. al. [5] achieved at $1000 \mathrm{~W}$ and 3 $\mathrm{m} / \mathrm{min} 1.6 \mathrm{~mm}$ and at $800 \mathrm{~W}$ and $3 \mathrm{~m} / \mathrm{min} 1.3 \mathrm{~mm}$. El Batahgy et. al. [7] achieved at $8 \mathrm{KW}$ $6.2 \mathrm{~mm}$ penetration at $0.5 \mathrm{~m} / \mathrm{min}, 4 \mathrm{~mm}$ at $1 \mathrm{~m} / \mathrm{min}$ and $3 \mathrm{~mm}$ at $1.5 \mathrm{~m} / \mathrm{min}$.

\subsection{Mechanical properties}

Table 3 shows that the ultimate stress and max strain at zero focal point. It is noted that the stress increases with increasing laser power at the same speed, and that the stress decreases at an increase in the speed. Due to the small surface area subjected to the load, the material was fractured at the weld area. To find out the type of fracture, SEM examination was occurred on the fractured sample. It was observed that the fracture of the material was ductile as shown in Figure 9.

Table 3 Maximum stress at different welding power and speed values

\begin{tabular}{cccc}
\hline Power $(\mathrm{W})$ & $\begin{array}{c}\text { Speed } \\
(\mathrm{m} / \mathrm{min})\end{array}$ & $\begin{array}{c}\text { Ultimate } \\
\text { Stress }(\mathrm{MPa})\end{array}$ & Elongation \% \\
800 & 0.5 & 580.53 & 1.58 \\
1000 & 0.5 & 631.85 & 2.55 \\
1000 & 1 & 385.77 & 1.72 \\
1200 & 0.5 & 605.21 & 3.92 \\
1200 & 1 & 474.09 & 2.18 \\
1200 & 1.5 & 521.52 & 1.23 \\
\hline
\end{tabular}

\subsection{Microhardness test}

Microhardness test is applied on selected welded samples to find out whether hardness is the same in different conditions or if there is any change in the hardness number. It is

as shown in Figure 10 and this is related to the non-uniform distribution of material contained in the weld zone which changes the behavior of the weld. This leads to a change in the hardness of the material. The increase in hardness number is due to the different phases present in the weld bead. The average values of

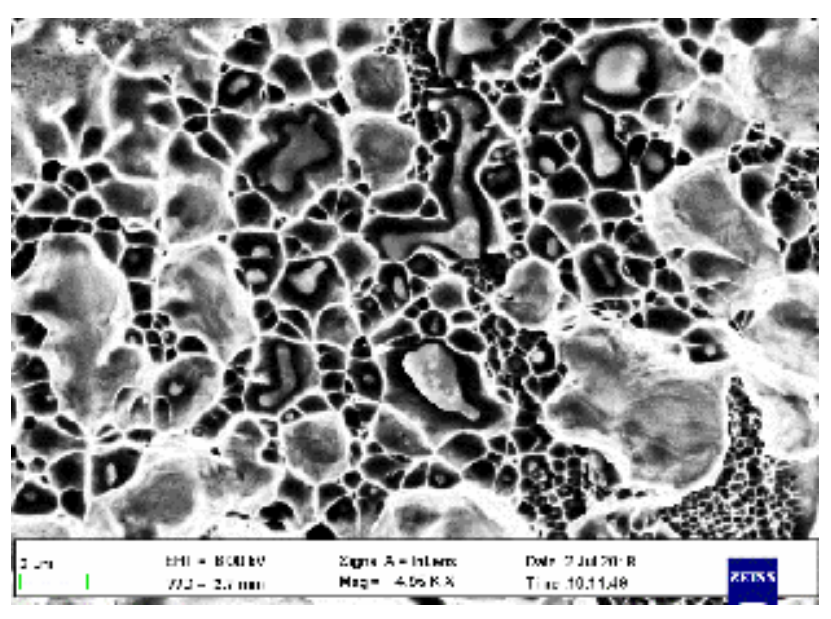

Figure 9 SEM image showing ductile fracture of welded sample at $1200 \mathrm{~W}$ and $0.5 \mathrm{~m} / \mathrm{min}$ 


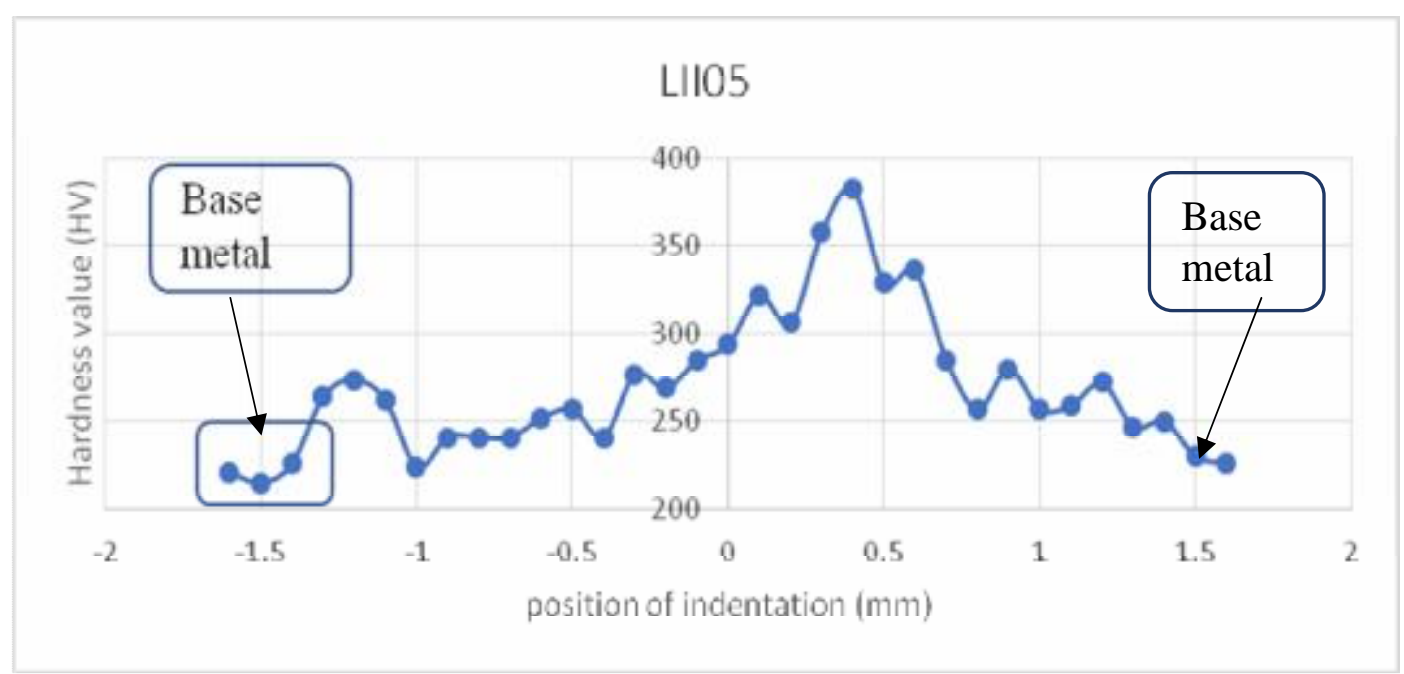

Figure 10 Variation of Hardness with distance from the center of the sample welded at 1200 $\mathrm{W}$ and $1 \mathrm{~m} / \mathrm{min}$

Several results have been obtained from the experimental work of laser welding of st her. These conclusions are listed as follows:

- The penetration depth increased from $121 \mu \mathrm{m}$ to $753 \mu \mathrm{m}$ when changing the power from $800 \mathrm{~W}$ to $1000 \mathrm{~W}$ and decreased to $687 \mu \mathrm{m}$ at $1200 \mathrm{~W}$ because of plasma and Marangoni.

- The power density was not high enough to melt the whole thickness of the material, and this is due to the low laser power at the chosen welding speed, which results in low depth of penetration.

- The lack of penetration has resulted in low strain ranges, Besides the fracture of the weld has occurred in the weld bead itself because the stress has been concentrated in the small weld

bead area.

- The stresses of the weld were increased by increasing laser power which proves the effect of increasing laser power in the depth of penetration.

- The SEM analysis has shown that the fracture of the material is ductile.

- The microhardness numbers of the welded samples are slightly higher than the numbers of the base metal, and this is due to different phases that appeared in the weld zone.

\section{REFERENCES}

[1] X. Na, Y. Zhang, Y. Liu, and B. Walcott, "Nonlinear identification of laser welding process," IEEE Trans. Control Syst. Technol., vol. 18, no. 4, pp. 927-934, 2010.

[2] C. Seang, A. K. David, and E. Ragneau, "Effect of Nd:YAG laser welding parameters on the hardness of lap joint: Experimental and numerical approach," Phys. Procedia, vol. 41, pp. 38-40, 2013.

[3] G. Wang, A. Wu, G. Zou, Y. Zhao, Q. Chen, and J. Ren, "Bending Properties and Fracture Behavior of Ti-23Al-17Nb Alloy Laser Beam Welding Joints," Tsinghua Sci. Technol., vol. 14, no. 3, pp. 293-299, 2009.

[4] A. Sun, J. Liu, and W. Liu, "The laser-beam welding of ferritic stainless steel for the motor vehicle exhaust 409L," Proc. 2011 Int. Conf. Electron. Mech. Eng. Inf. Technol. EMEIT 2011, vol. 8, pp. 3931-3933, 2011.

[5] M. M. A. Khan, L. Romoli, and G. Dini, "Laser beam welding of dissimilar ferritic/martensitic stainless steels in a butt joint configuration," Opt. Laser Technol., vol. 49, pp. 125-136, 2013.

[6] X. Xue, A. Pereira, J. Amorim, and J. Liao, "Effects of Pulsed Nd:YAG Laser Welding Parameters on Penetration and Microstructure Characterization of a DP1000 Steel Butt 
Joint," Metals (Basel)., vol. 7, no. 8, p. 292, 2017.

[7] A.-M. El-Batahgy, A.-F. Khourshid, and T. Sharef, "Effect of Laser Beam Welding Parameters on Microstructure and Properties of Duplex Stainless Steel," Mater. Sci. Appl., vol. 2, no. 10, pp. 1443-1451, 2011.

[8] A.-M. El-Batahgy, "Laser Beam Welding of Austenitic Stainless Steels-Similar Butt and Dissimilar Lap Joints," Weld. Process., pp. 93-116, 2012.

[9] Y. Feng, Z. Luo, Z. Liu, Y. Li, Y. Luo, and Y. Huang, "Keyhole gas tungsten arc welding of AISI 316L stainless steel," Mater. Des., vol. 85, no. November, pp. 24-31, 2015.

[10] M. Bolut, C. Y. Kong, J. Blackburn, K. A. Cashell, and P. R. Hobson, "Yb-fibre laser welding of $6 \mathrm{~mm}$ duplex stainless steel 2205," Phys. Procedia, vol. 83, pp. 417-425, 2016.

[11] W. M. Steen and M. J., Laser Material Processing, vol. 1, no. 0. 2010.

[12] T. Zacharia, S. A. David, J. M. Vitek, and T. Debroy, "Weld Pool Development during GTA and Laser Beam Welding of Type 304 Stainless Steel, Part II - Experimental Correlation," Weld. J., vol. 68, no. December, pp. 510-520, 1989. 